\title{
TECNOPoÉtICAS SUbALTERNAS (O ALGUNOS APUNTES PARA DESANDAR TERRITORIOS)
}

\section{Subaltern Techno-Poetics (or Some Notes to Retrace Territories)}

\author{
Mariela Yeregui* \\ DOI: https://doi.org/10.29043/liminar.vl8i2.759
}

Resumen: El campo de las prácticas artísticas tecnológicas latinoamericanas habilita debates y discusiones en torno a categorías tales como "mestizo" o "híbrido" a partir de su condición de imbricación entre la centralidad tecnológica y las "prácticas situadas". Los discursos de la tecnocultura, marco en el que estas producciones tienen lugar, suscitan replanteamientos en los artistas locales, para quienes la centralidad tecnocientífica debe ser objeto de fricción y de desarme crítico. A través de este artículo propongo examinar algunos proyectos tecnoartísticos en el ámbito latinoamericano que aportan una mirada decolonial en relación con el diálogo arte-tecnología.

Palabras clave: arte contemporáneo, tecnología, tecnoestética, hibridación, descolonización, territorio.

Abstract: Latin American technological art generates debates and discussions around categories such as "mestizo" or "hybrid" that arise from the overlap between the importance of technology and "situated practices." The discourses of techno-culture, and the framework in which these productions take place, lead to reconsideration from local artists, for whom the techno-scientific centrality is a motive of friction and requires critical dismantling. In this article, I examine some techno-artistic projects in Latin America that provide a decolonial view of the ongoing dialogue between art and technology.

Keywords: contemporary art, technology, techno-aesthetics, hybridity, decoloniality, territory.

\footnotetext{
* Mariela Yeregui. Doctora en Filosofía de los Medios por la European Graduate School, Suiza. Directora de la Maestría en Tecnología y Estética de las Artes Electrónicas, Universidad Nacional de Tres de Febrero, Argentina. Temas de especialización: arte, tecnología tecnopoéticas, acción/intervención artística, decolonialidad. Correo electrónico: myeregui@untref.edu.ar. ORCID: https://orcid.org/00000003-0550-2352
}

Enviado a dictamen: 11 de diciembre de 2019. Aprobación: 21 de abril de 2020.

Revisiones: 2. 


\section{¿Lo mestizo? ¿Lo híbrido? Lo ch'ixi}

$\mathrm{M}$ estizaje, hibridez y transculturalidad son términos que plantean matices semánticos categóricos del orden de lo histórico, lo teórico, lo filosófico y de la vivencialidad concreta, en contextos donde dichos conceptos afloran con mayor persistencia, como ocurre en el caso de Latinoamérica. Si a esto se suma que dichos conceptos son el disparador y el fusible para una experiencia de imbricación con tecnologías y lenguajes portadores de capitales semánticos fuertemente arraigados en espacios centrales de la discursividad tecnocientífica, la conflictividad emerge con mayor potencia.

Se trataría, entonces, de desarmar el andamiaje ideológico y la arquitectura de presupuestos, que vehiculizan una cierta noción de "mestizaje", desde las prácticas artísticas que se articulan en proyectos en los que lo tecnológico aflora como herramienta, lenguaje, discurso o poética. Es preciso pensar - el pensar activo que se encarama sobre el hacer pensativo, ambos inherentes a las prácticas artísticas - cómo abordar la articulación de la tecnología con el arte desde lo que Walter Mignolo concibe como "pensamiento fronterizo": una condición de existencia de los proyectos "desoccidentalizadores" y "decoloniales" (Mignolo, 2003).

El propósito de este recorrido no es conclusivo. Muy por el contrario, propongo abordar ciertas experiencias artísticas de cruce entre arte y tecnología en el contexto latinoamericano para sugerir algunas vías de entrada que permitan pensar, explorar y dar contextura crítica a posibles fricciones, diálogos, disputas, controversias y retroalimentaciones entre la dimensión tecnológica y la artística.

Los casos tratados no pretenden cubrir el amplio espectro de la producción tecnoartística latinoamericana. Son solo brotes que emergen en un campo diverso y ecléctico. Lo que sí tienen en común todos ellos es la idea de desarmar y desguazar la "caja negra" tecnológica poniendo en el centro cuestiones que refieren a lo que, provisionalmente, voy a llamar "mestizaje".
En relación con la noción de "mestizaje", lejos de pretender agotar un tema que es por demás vasto y que ha sido abordado profusamente por diversos autores, quiero referirme brevemente aquí a ciertos matices - a veces no tan leves y la mayoría de las veces sumamente palmarios a la hora de definir ciertos términos- que configuran y refieren al espacio de lo transcultural. Aunque sucinta, esta referencia a cierta génesis conceptual se ve motivada por la necesidad de asumir un punto de partida, un disparador que articule mis propios pespuntes de pensamientos y de prácticas al hacer propia la tecnología, no solo como herramienta sino también -y fundamentalmente- como objeto gnoseológico.

Desde su versión histórica, ligada a los resabios y a las permeaciones coloniales en nuestro continente, el término mestizo aparece asociado a la idea de mezcla. Dicha argamasa racial y cultural emerge como un todo indiferenciado, como una mixtura espuria con fuertes connotaciones negativas, en la que el acento recae sobre el resultado y no sobre el proceso. A la luz de la modernidad, durante buena parte de los siglos XIX y XX, y con el sujeto-hombre - que no es cualquier sujeto-hombre sino el blanco y occidental-, el sermestizo es objeto de miradas condescendientes en las que la mezcla aparece como una síntesis armoniosa. Lo "heterogéneo", bajo el espejismo de lo sincrético - ciertamente desde una perspectiva de asimilación y domesticación - deviene un eslabón fundamental para la construcción del mito de nación moderna. Habría que esperar a los años sesenta y setenta del siglo XX para que la noción de mestizaje se afrontara desde una matriz diferente. Fue entonces cuando surgió la noción de "hibridación" como categoría de análisis de estos procesos de disyunción cultural, social y étnica. A partir de las teorías poscoloniales - Bhabba y Spivak, entre otros-, surgidas a la luz de las independencias de la segunda mitad del siglo XX, el concepto de hibridez — con fuertes raíces biológicas pero también con influencias de los conceptos de heteroglosia y polifonía de Bajtin (1982) — permite pensar las formas de subversión y fricción, posicionando esta diversidad muy por fuera 
de la armonía simetrizante que suponía el concepto de mestizo.

Para Néstor García Canclini, por su parte, las culturas híbridas dan cuenta de la coexistencia de lo homogéneo y lo heterogéneo, de la juntura de estructuras que existían separadamente, y que unidas forman nuevas organizaciones y sentidos. Para el autor:

[...] el objeto de estudio no es la hibridez, como algo ya consolidado o producido, sino los procesos de hibridación. Es esta diferencia lo que permite reconocer que hay procesos no sólo de fusión sino de desgarramiento, e incluso aspectos que no llegan a ser hibridados. Una teoría no ingenua de la hibridación es inseparable de una conciencia crítica de sus límites. Debe distinguir lo que se impone como hibridación o lo que no se deja o no quiere o no puede ser hibridado. De manera que vemos así la hibridación como algo a lo que se puede llegar, de lo que es posible salir, un proceso en el que aparece lo que podríamos llamar insoluble, lo que nunca resuelve del todo, las diferencias y desigualdades presentes en los procesos de hibridación (García Canclini, 2001).

Sin embargo, si bien el autor admite cierta dosis de adherencia en estos procesos hibridatorios, habría instancias en las que la fusión - aunque no sea ocasionalmente - resulta posible. Para la teórica boliviana Silvia Rivera Cusicanqui, en cambio, la disyunción es mucho más radical. Partiendo del concepto aymará de lo ch'ixi - un "gris jaspeado formado a partir de una infinidad de puntos negros y blancos que se unifican para la percepción pero permanecen puros, separados" (Rivera, 2015:95) - elabora un concepto de mestizo que despliega su potencia insurgente. Chi'xi es una poderosa metáfora para hacer referencia a un tipo de mestizaje que reconoce la fuerza de lo indígena y la potencia de lo europeo. Porque, para la autora, "lejos de la fusión o de la hibridez, se trata de convivir y habitar las contradicciones. No negar una parte ni la otra, ni buscar una síntesis, sino admitir la permanente lucha en nuestra subjetividad entre lo indio y lo europeo" (Rivera, 2019b).
De fuerte cuño occidocentrista, ${ }^{1}$ el ideologema que porta la tecnología no puede dejar de ser revisitado cuando se trata de explorar proyectos desarrollados en nuestro contexto latinoamericano. Resulta muy difícil no asociar los discursos tecnoartísticos a los marcos epistemológicos que sustentan los programas de la ciencia moderna. Pero, como nos recuerdan los teóricos de la decolonialidad, "no hay modernidad sin colonialidad" (Mignolo, 2003:34) o, como dice Grosfoguel, "la colonialidad y la modernidad constituyen dos lados de una misma moneda" (2007:27). En consecuencia, y siguiendo los trazos de las corrientes decoloniales, propongo examinar algunas producciones artístico-tecnológicas producidas en el contexto de América Latina y, más específicamente, las que articulan dinámicas, discursos, retóricas y lenguajes que se adhieren y, a la vez, interpelan a la naturaleza y a la tecnología.

Antes de embarcarme en la tarea de transitar por algunas de las prácticas tecnoartísticas que operan desde la subalternidad, es preciso recordar que "la inflexión decolonial" (Restrepo y Rojas, 2010) supone un giro paradigmático que permite romper con epistemologías dominantes y civilizatorias. Desde una mirada decolonial —esta suerte de bisagra epistemológica-, propongo rebasar aquellos enfoques fuertemente teñidos de miradas euro u occidocentristas a la luz de producciones que se apartan de dichos paradigmas. Trabajos que desertan del espectro tecnocientífico al no quedar entrampados en la "cientifización" de las prácticas. Proyectos que plantean otros derroteros, fundados en un "estar-siendo" con el entorno, donde las prácticas tecnológicas se adhieren para que sus procesos discurran de una manera "situada" $\mathrm{y}$ crítica. Lo que me interesa es poner el acento y visibilizar experiencias concretas que parten de una radicación y compenetración territorial, rompiendo con paradigmas normalizados y hegemónicos. Prácticas que ponen en juego una cierta fenomenología del cruce arte/ tecnología y que parecen sugerir que la incorporación de lo tecnológico a la obra - a las materialidades concretas- puede transitar por caminos diferentes de aquellos que emprenden los discursos tecnocráticos 
dominantes, dejando así paso a experiencias que, en definitiva, articulan escenarios de vida.

El territorio de las modernidades periféricas asume configuraciones diferenciales. Esta territorialidad singular emerge en los trabajos de algunos artistas tecnológicos latinoamericanos de una manera neta y con un vigor expresivo que señaliza y enfatiza la emergencia del Otro, desafiando ciertos postulados medulares de la modernidad. El antropocentrismo, cimiento de la visión moderna, es desmantelado así y relegado hacia otras latitudes.

\section{Lo tecnológico y lo ch'ixi}

Los paradigmas que sustentan lo tecnológico se encuentran rotundamente anclados en el universo de la modernidad y, por ende, fuertemente vinculados a la idea de progreso, de funcionalidad, y a principios tecnocráticos; todos ellos susceptibles de ser analizados y puestos en crisis en un contexto latinoamericano donde la modernidad es un concepto ilusorio o, al menos, problemático. Es esta discursividad hegemónica de la modernidad la que permea y sostiene una construcción de mundo, con lógicas propias y expandidas. Y esta articulación penetra en el régimen latinoamericano de producción de verdad asumiendo la necesidad de generar una narrativa en torno a la modernidad para superar la barbarie y emular al Otro-civilizado.

Frente a esto, son varios los artistas latinoamericanos que plantean derroteros subalternos, articulando miradas críticas o problematizando la propia materia tecnológica. Ciertamente los proyectos que cruzan arte y tecnología en el ámbito latinoamericano son diversos y heterogéneos. Sería ingenuo plantear una unidad y mucho menos abrigar la ilusoria pretensión, de carácter ontológico, acerca de una supuesta "latinoamericanidad". Muy lejos de pretender operar una mirada reduccionista y generalizante, quiero hilvanar experiencias ajenas y propias que plantean un cierto desmembramiento y desguace del aparato -y no me refiero solo al dispositivo técnico sino, fundamentalmente, al dispositivo que define
Foucault - ${ }^{3}$ poniendo en jaque a la misma lógica del pensar/hacer artístico tecnológico. Porque no se trata solo de los objetos resultantes, sino además de los sistemas que sostienen y emergen de la operación artística.

Entre estas posibles fricciones en clave ch'ixi, o dentro de estas "políticas del desvío ligadas a una desinstrumentalización del fenómeno técnico occidental" (Kozak, 2014:10), distingo tres estrategias básicas cuyos límites son, por demás, porosos:
a. el desguace epistémico,
b. el desguace poético,
c. el desguace tecnológico.

Para el filósofo argentino Rodolfo Kusch, la técnica occidental y la mirada que la misma prevé se sostienen sobre la lógica de lo esperable, lo asible, lo concebible. Más allá de estos límites, sobreviene el temor por el derrumbe de un saber orientado hacia la idea de "progreso", porque, para este autor, la "técnica implica esencialmente una puesta en práctica de lo que se espera [...]" (Kusch, 2000:10). Lo que propone el filósofo, en definitiva, es pensar otros derroteros epistemológicos, situados en el ámbito del continente mestizo, para trascender ese saber instrumental, ese saber de la ciencia moderna, netamente occidocentrista.

\section{Desguazar la naturaleza}

Por lo anterior considero valioso aludir a estos "desguaces epistémicos" dentro de estas prácticas locales en las que la mirada de los artistas se entreteje con la naturaleza, por fuera de las fronteras - no solamente físicas sino también epistémicas - del laboratorio, en tanto topos paradigmático de la ciencia moderna. Me refiero concretamente a los trabajos de Gabriela Munguía, que muy visiblemente delinean otros puntos de vista en relación con el entorno: superan la exterioridad de la mirada antropocéntrica para plantear un "estar-siendo" en términos kuscheanos: un estar situado en la indeterminación, una humanidad dinámica en un acontecer empírico y particular. 
Los trabajos de esta artista mexicana, afincada en Buenos Aires, logran trascender el trauma del usuario de una tecnología fundada en plataformas epistemológicas que sustentan una centralidad científica y técnica, repeliendo, en contraposición, la seducción de la hegemonía bioartística en cuanto a estrategias fundamentadas en el trabajo con materiales biológicos, desde los paradigmas de la ciencia moderna. Las prácticas referidas son prácticas situadas que se incrustan en el territorio. Munguía lo expresa cabalmente cuando dice:

Entender la vida es la manera de trabajar con la naturaleza porque hay que entenderla en el territorio. La naturaleza no como una proteína, no como un aminoácido, no como un ADN sino como un gran sistema y así descentralizar el lenguaje humano para permitir otros lenguajes, otras semánticas, otras dialécticas y descomponer el pensamiento antropocentrista. Uno no vive en el vacío, vive en el territorio. Hay que descentralizar las cajas del conocimiento. En Latinoamérica, el artista vuelca lo vivo al territorio. ${ }^{4}$

En una de sus obras, Habitáculos orgánicos, ${ }^{5}$ Munguía imagina el territorio urbano como una compleja organización biológica. En este proyecto, a través de tecnologías de bioimpresión, se producen pequeños cubos hechos de agar-agar que se van agrupando en una serie de estructuras. Estos cubos componen microarquitecturas que remedan ciudades a pequeña escala. Los habitáculos creados por la artista se proponen como una morada para microorganismos, los que a su vez, a partir de procesos biológicos, transforman estas moradas, redibujando así el territorio. Estos pequeños sistemas arquitectónicos, poblados por colonias de bacterias y hongos, enhebran en su interior una multitud de vínculos de interacción, intercambio, crecimiento y descomposición. La forma en que los microorganismos habitan cada uno de los habitáculos hace que el paisaje cambie constantemente merced a la proliferación de minúsculos seres vivos. La documentación del proceso de biogeneración a través de impresoras 3D acompaña al objeto en una pantalla aledaña.

Para Munguía, la posibilidad de imaginar nuevas relaciones con el territorio, a partir de deconstruir lo urbano desde una perspectiva biológica, hace posible repensar las dinámicas demográficas, sus flujos y fluctuaciones, desde la utopía del nuevo urbanismo: las ciudades como un gran organismo vivo. Un espacio dinámico donde la propia estructura edilicia es alimento y sedimento a la vez, mutando en función de los procesos vitales de sus habitantes. El trabajo está atravesado por una mirada escéptica en relación con los procesos de industrialización, haciendo emerger nuevas formas de entender y de concebir el territorio. En este desguace, la dimensión epistemológica de lo tecnológico - por sobre su dimensión utilitaria - aparece en primer plano. El dispositivo no es entonces un elemento funcional, sino el resultado de aplicar el conocimiento científico existente a problemas prácticos. En el trabajo de Munguía, lo tecnológico organiza sistemas complejos portadores de nuevos conocimientos: micromundos que resultan escenarios idóneos para examinar a escala comportamientos sociales y políticos más generales. La caja negra es boicoteada, y plantea nuevos resquicios por los que la industrialización se posiciona en otros soportes paradigmáticos: aquellos en los que la combinatoria vital, orgánica y no dominante - desde una perspectiva bottom-up- ${ }^{6}$ permite concebir arquitecturas abiertas, sensibles y efímeras. En definitiva, la obra de Munguía trasciende el utilitarismo tecnológico para adentrarse críticamente en el basamento tecnológico y, desde allí, articular una mirada políticamente incisiva sobre los actuales procesos de industrialización.

\section{Desmantelar la tecnología}

La obra Fonoraggy ${ }^{7}$ de Federico Gloriani, por su parte, es un ejemplo elocuente de cómo desde la puesta en abismo de lo tecnológico, removiendo sus basamentos epistémicos - a partir de dispositivos anacrónicos y perimidos-, se moldean dispositivos disruptivos que 
tensionan los límites entre el arte y las técnicas. En particular, se trata tanto de un gesto a nivel de lo que lo tecnológico conlleva como dispositivo de construcción de conocimiento - la episteme artística, ${ }^{8}$ en este caso (desguace epistémico)-, como de una acción que horada los propios cimientos de la caja negra de la tecnología (desguace tecnológico).

El disparador de la obra involucra al artista húngaro László Moholy Nagy quien, dictando por teléfono indicaciones de color, tamaño y forma, encargó a una fábrica cinco pinturas sobre porcelana esmaltada. Por su parte, Fonoraggy, un aparato con reminiscencias de universos de telecomunicaciones obsoletas, imprime la información de color de cada uno de los píxeles de una versión digitalizada de la pintura Rincón de estudio (1946), del pintor argentino Fortunato Lacámera — sin violar los derechos de propiedad y reproducción-, a partir de un sonido codificado que le llega por línea telefónica. Se trata así de un sistema de traducciones en cadena: de la información física de la pintura se pasa a una codificación sonora a partir de una traducción digital, que a su vez se transmite por línea telefónica para ser impresa por medios digitales en un soporte físico. Absurda y paródicamente, un papel continuo con información numérica transcribe píxel a píxel la información visual de la pintura, en una operación que llevaría aproximadamente catorce meses de ejecución. El trabajo despliega así una secuencia de acciones que no hacen sino encriptar y desencriptar continuamente la información, tensando y desbaratando la propia caja negra y teniendo como resultante la delusoria opacidad del código. El complejo sistema de transposiciones y decodificaciones que propone la obra, a partir de procedimientos low tech, lanza una mirada crítica y despiadada en relación con los universos comunicacionales, desestabilizando así a las máquinas y a las tecnologías, a los dispositivos y a los códigos, a la figuración y a la desfiguración. Pero, sobre todo, la obra hace tambalear los presupuestos que sustentan el aparato tecnológico: la eficiencia, la precisión, la rapidez y la economía del código.

\section{El territorio y sus desguaces poéticos}

La poética del territorio - mayormente asentada en la idea de "desguace poético"- no está ausente en la exploración de los artistas tecnológicos latinoamericanos. En el campo del arte electrónico, y en un número considerable de obras locativas, la relación con el Otro queda muchas veces reducida a juegos de interacciones con dispositivos e interfaces físicas diversas - trátese de interfaces discretas o continuas pero que a la larga no logran superar cierto binarismo del input y el output-, y cuya dinámica se concentra en el rol monopólico de la interfaz. Así, la noción que de este tipo de interfaces se desprende, muy habitualmente pone en escena una lógica basada en la naturaleza responsiva del dispositivo, por el que el territorio pierde, paradójicamente, su territorialidad y emerge como una mera representación. Innumerables son los ejemplos, en el caso del arte tecnológico locativo, en los que el dispositivo es asumido de manera acrítica $y$, en consecuencia, su lógica se basa únicamente en el accionar de botones, pantallas u otros sistemas de entrada de los que no se espera más que una salida, un efecto, es decir, una consecuencia de las acciones del usuario con esta interfaz. ${ }^{9}$ En estos casos, se dialoga con la interfaz y no se construye una dimensión discursiva, relacional o contextual y toda posibilidad de "desguace poético" queda así anulada. Una relación input-output en la que la relacionalidad se diluye bajo el espejismo del efecto tecnológico. No se interactúa con Otro - el otrosujeto, el otro-territorio, el otro-contexto, etcétera-.

La cuestión de la interfaz en el campo de las creaciones electrónicas y digitales es un tópico obligado. Muchos teóricos han escrito largas páginas acerca de la relevancia de la interfaz en la dinámica de la interactividad. De todo este andamiaje teórico en torno al concepto, retengo algo repetido hasta el hartazgo: su carácter de intermediación. Superficie de contacto, profundamente engarzada en el marco de un sistema informático, capaz de procesar señales de entrada y de salida. Pero también es importante notar que la relación mapa-territorio no es caprichosa a la hora de referirse al concepto de interfaz. El texto de Borges 
"Del rigor en la ciencia" dio pie para que Baudrillard desarrollase extensamente su concepto de simulacro: ¿cuál es el territorio y cuál el mapa? (Baudrillard, 1984). De la misma forma, esta superficie de contacto, en un mundo regido por los medios, es el espacio de acción más usual. Las relaciones y diálogos priorizan el mapa, en el sentido de "calco" al que alude Deleuze (1990), sobre el territorio.

Muchas veces hay en la mediación técnica un capricho oscurantista por el que el porqué y el cómo de la relación intersubjetiva o interobjetiva develan motivaciones aleatorias y, a veces, fútiles y caprichosas. ¿Qué sucede cuando un GPS nos entrega las coordenadas geográficas de nuestra ubicación? El dispositivo no hace sino lo que se espera que haga. ¿Y cuando este mismo dispositivo es parte de un proyecto que se pretende artístico y también nos entrega los datos de geolocalización y no más que eso? Aquel que lo manipula, artista o público, se convierte en un usuario tecnológico, perdiendo toda posibilidad de generar relaciones significativas con el territorio. Nuevamente, interactúa con una interfaz y se pierde toda posibilidad de construcción crítica y simbólica. Sin embargo, afortunadamente muchos proyectos echan por tierra estos presupuestos y aspiraciones tecnocráticas y plantean superar las encrucijadas de los tecno-discursos para pensar en flujos de interacciones en entornos en los que el conflicto articula las propias prácticas.

El fenómeno de la territorialización moderna, a partir del desarrollo ferroviario y de su posterior y reciente privatización que culminó en su destrucción, es un fenómeno que se repite en varios de los países de América Latina. En ese sentido, resulta revelador el proyecto SEFT-1 ${ }^{10}$ (Sonda de Exploración Ferroviaria Tripulada) de los artistas mexicanos Iván Puig y Andrés Padilla Domene.

Según los autores, la SEFT-1 es un vehículo que funciona como dispositivo de investigación. De aspecto futurista, multiforme y amorfo al mismo tiempo, este vehículo puede desplazarse tanto en tierra como en vías férreas, produciendo encuentros con la gente y realizando una bitácora fotográfica, de video, sonora y textual. Esta información fue publicada en un sitio web, ${ }^{\text {Il }}$ desde el cual era posible monitorear, gracias a un GPS, el estado, la ubicación, las rutas del vehículo, visualizar imágenes y videos, y acceder a información contextual.

La deriva de la SEFT-1 no hace sino producir la eclosión del territorio, reafirmando así la emergencia de este como variable locativa privilegiada. El territorio desplaza a la locación, y si bien la ubicación —en tanto componente matricial de la locatividad - es una de las variables que hacen visible el trayecto de la nave de exploración férrea, son los territorios discursivos los que brotan y descubren los efectos y las huellas de la desterritorialización moderna. Y el apogeo y la destrucción del tren y del metadiscurso que sustenta un proyecto de modernidad contradictoria y heteróclita -donde conviven trenes y burros, autopistas y polvorientos caminos, eurocentrismo remilgado y regionalismo exacerbado- son jaqueados por el tránsito de este singular vehículo.

La articulación del pasado y del futuro a través de las acciones del presente -implícita en el concepto de territorio- es puesta de relieve por el presentecontinuo instalado a partir de los recorridos del vehículo por las vías. Pero además, las vías son la transición hacia la geografía del vestigio que se resignifica y que abre nuevas escenas. En suma, la reterritorialización se produce en esta encrucijada que re-enlaza nostálgicamente al pasado a través de la visibilización del fracaso de un modelo - "el futuro ya no es lo que se creía que iba a ser"-, que re-conecta críticamente con nuevos modelos - "el futuro es lo que no fue"-y que instala la dimensión del presente. Así, el desplazamiento y los retazos de otras escenas se unen en una suerte de conjuro contra el anquilosamiento, la estrechez de horizontes, los "juegos finitos". Sobre los jirones de un mapa férreo - las propias vías como trazas de la ausencia - se produce la acción, no como dibujo del terreno - calco-, sino como verdadero mapa que engendra nuevas territorializaciones. José Luis Barrios analiza cómo en este proyecto actúan las modernidades heterotópicas en tanto reordenación de la ruina. 
En una suerte de historia a contrapelo, la estética deliberadamente low de la Sonda de Exploración, unida a la inversión de la función de las vías del tren que transitan hacia los lugares abandonados del progreso, funcionan como la activación de un pathos que no pasa por lo onírico - por el sistema especular - sino por la naturaleza, por las pulsiones elementales de la vida que aparecen como instinto que desmonta la falacia de la modernidad (Barrios, 2011:218).

Desmontar, deshacer, desarmar. Pero, ¿cómo podría deshacerse lo que nunca fue hecho, pensando en el hacer como acción y no como la creación de algo? ¿Cómo desguazar el vacío? He aquí la contradicción a la que hace frente el proyecto aludido.

En definitiva, esta nada - lo que no fue, la promesa temporal de una acción que nunca se produjorepercute en el espacio. Deja sus trazas, sus huellas, por medio de los vestigios. Crea un territorio de agujeros semánticos, de esbozos disfuncionales, de sedimentos de deseos incumplidos, de imaginarios fuera de rango.

Y nuevamente Barrios aporta claves esenciales para escudriñar el escenario de estas estrategias disruptivas:

Acaso por ello la urgencia de ensanchar el horizonte del discurso hacia esos límites que se pensaron superados, hacia la crítica política y la crítica del progreso, hacia las formas y las genealogías que definieron los horizontes de acción del progreso y sus formas de instrumentalización en la técnica. Una ampliación que supone repensar la función de la representación en el arte contemporáneo, pero sobre todo, pensar la modernidad en los lugares donde deviene en fisura, pensarla en sus trazos paralelos, ahí donde las vías del tren quizá no lleven a ninguna parte [...] (Barrios, 2011:219).

Frente a las operaciones territoriales fundadas en el concepto de locatividad, en donde los espacios se visibilizan en términos cartesianos, las improntas técnicas determinan los discursos y la tecnología recibe loas, las derivas a las que me refiero alumbran territorios resquebrajados, sumergiéndose en la dimensión histórica, política, social y cultural para trazar líneas de fuga que posibilitan nuevos escenarios de acción y de pensamiento.

Hay en esta acción reterritorializadora un desguace poético y político que desmaleza la conflictividad de la modernidad. El territorio es interpelado y surcado por un tipo de acción que despliega la potencia de lo ch'ixi, la tensión insoluble entre estos dos principios estructurantes, poniendo en escena la ruina de la modernidad.

En suma, los proyectos aludidos carcomen los cimientos de los paradigmas tecnológicos al operar en los regímenes de producción, de definición y de creación de y por lo tecnológico, desmantelando los puntales de la propia tecnología y proponiendo un escenario de tensión a partir de "prácticas tecnológicas situadas", porque, parafraseando a Rivera Cusicanqui, "un mundo ch'ixi es posible". ${ }^{12}$

\section{Todas las utopías son deprimentes}

Bordes (Todas lasutopías son deprimentes), trabajo que realicé en coautoría con Marlin Velasco, surgió en el marco de un proyecto de creación/investigación dentro de la universidad..$^{13}$ En el proyecto se propuso una dinámica de trabajo basada en el concepto de deriva. Se abordaron problemáticas específicas en un entorno propio y abierto desde el cual se implementaron estrategias de experimentación creativa inscriptas en el ámbito del arte, la acción, la tecnología y el territorio, que pusieron en crisis las nociones de mestizaje y de hibridez y cómo estas resuenan en el escenario local de Buenos Aires.

En este caso concreto, las activaciones, producto de acciones y recolecciones específicas sobre el territorio, se realizaron en los bordes de la Avenida General Paz. Esta calle es una de las pocas avenidas concéntricas de la Ciudad de Buenos Aires, trazada en el plano de la Federalización ampliada de 1887. Es de gran importancia estructural, de intenso tránsito, en la que se realizaron sucesivas ampliaciones, y con una progresiva pérdida de su carácter original de parkway. ${ }^{14}$ Da cauce al flujo de un fuerte crecimiento urbano que 
ha tenido un impacto importante en su estado vial, la congestión vehicular, la situación del transporte, los servicios públicos, los índices de accidentes, la saturación poblacional y el consecuente incremento de los niveles de pobreza y exclusión social. Los procesos de desindustrialización que tuvieron lugar entre 1970 y 1990 en Argentina hicieron de esta arteria el escenario de conformación de territorios de abandono - fábricas quebradas y aglomeraciones urbanas marginalizadas del sistema productivo- y una zona franca de circulación de grandes grupos poblacionales hacia la Ciudad de Buenos Aires. En sus bordes se suceden un sinnúmero de "espacios residuales" (Careri, 2016), entendiendo estos como aquellos en los que se produce una desestructuración de la lógica urbana, por un lado, pero al mismo tiempo se generan otras tramas alejadas de la oficialidad urbanística: pasacalles, santuarios del Gauchito Gil, ${ }^{15}$ parrillas al paso, etcétera (ver Imagen l).

A partir del concepto de "espacios residuales" de Francesco Careri se generaron estrategias y dispositivos de acción y visibilización de recorridos, alumbrando en cada uno de ellos zonas de desestructuración urbana. El proyecto planteó (y plantea) acciones en el territorio - habitaciones temporarias, diálogos, recolecciones-y una posterior articulación de todo ello en el marco de una instalación polimorfa. El proyecto aborda así problemáticas específicas en un contexto dinámico desde el cual se implementan estrategias de experimentación creativa situadas.

Francesco Careri dice que "el andar, el estar ahí, es un acto democrático de reapropiación del espacio público, en cierto modo un acto revolucionario" (Careri, 2016:89). Este es un proyecto de caminar, pensando que el caminar produce activaciones vitales de apropiación y de resignificación del paisaje. Pero no de cualquier paisaje, sino de aquel que aparece en las cunetas al borde de la General Paz, en los lugares residuales del conurbano, en los espacios de transición entre la centralidad urbana y sus periferias.

La ciudad moderna se configura como un espacio "otro", que entraña diversas y profundas transformaciones en los modos del "ser social". Haciendo propios los conceptos de Buck Morss (2005), la ciudad moderna se constituye así en un mundo de ensueño y catástrofe que se balancea entre las utopías "urbanistas" y los "infiernos" urbanos poblados por espacios segregacionistas - como por ejemplo, las autopistas- y por espacios en los que el conflicto emerge. Es en estas zonas disruptivas donde toma cuerpo el proyecto.

Propusimos así una dinámica de trabajo en la que los desplazamientos, a partir de impulsos que favorecieran la emergencia de los intersticios, hicieran surgir una mirada crítica en relación con las cartografías tradicionales, reforzada a su vez por dispositivos tecnológicos - y no tanto- de factura artesanal.

¿Cómo reinterpretar en los desplazamientos al territorio y contraponer de ese modo nuevas cartografías a los mapas aéreos dominantes de Google Maps? ¿Cómo hacer interactuar la visión cenital con una visión desde el territorio para generar un contrapunto visual sensible a partir de la propia experiencia territorial? ¿Cuáles son los límites y bordes experienciales que permitirían reformular las visiones normalizadas de los mapas?

Provistas de un carro, fabricado por nosotras e intervenido con técnicas textiles, caminamos durante noventa días, mínimo dos horas diarias, por la franja aledaña a la mencionada avenida. Para nuestras caminatas, desarrollamos un software de visualización de recorridos, a partir de la detección de trayectorias, vía GPS. Se elaboraron dispositivos específicos portables - lo que comúnmente se denomina wearable-, de bajo costo, embebidos en la vestimenta que nosotras diseñamos y creamos, compuestos de un minidisplay LCD de 1.7 pulgadas - cinco centímetros aproximadamente-, blanco y negro, con el GPS incorporado. Sobre los mismos, se dibujaron en tiempo real los trayectos. Durante el proyecto se utilizó un display por día — noventa displays en total- que grafica de manera muy sencilla, con líneas netas, el recorrido de la jornada, haciendo dialogar la línea del dibujo manual con la del digital. Estos noventa displays se montaron posteriormente, en el espacio expositivo, sobre una estructura textil, y dan cuenta de manera progresiva, en formato audiovisual, de los recorridos llevados a cabo (ver Imagen 2). 
Asimismo, durante los recorridos se produjeron reinterpretaciones visuales de los trayectos en formato textil: mapas bordados, otros en capas de telas transparentes - remedando las composiciones en capas de los programas informáticos de diseño de imagen - y un gran recorrido cartográfico electrotextil. Todos estos materiales desafían la univocidad de la representación cartográfica canónica (ver Imagen 3).

Se hicieron también campañas de recolección de objetos desechados, que pasaron a componer una suerte de arqueología de esta espacialidad residual. Entre los objetos recolectados había chatarra electrónica que se refuncionalizó y se restituyó al ecosistema urbano, a través de incrustaciones en los muros agrietados, lo que permitió a sus habitantes interacciones simples con ellos —encendido de diodos, motores, etcétera- (ver Imagen 4).

Echando mano a las ideas de Deleuze y Guattari (2002), postulamos en nuestro accionar que la unidad mínima de lo real no es la palabra ni el concepto ni el significante, sino el agenciamiento, entendido este como una línea de fuerza que atraviesa la totalidad de las ideas, de los elementos, de los cuerpos. Estas líneas envuelven relaciones metamórficas en cuanto a la territorialidad, siendo las de fuga aquellas que plantean la emergencia de la desterritorialización. Es una relación multidimensional que implica un cofuncionamiento colectivo. Se trata de un andamiaje imperceptible que sostiene y acciona las relaciones. Todo agenciamiento es siempre territorial, diría Deleuze (1990).

Los desplazamientos plantean un territorio donde la conflictividad insinúa mapas posibles de exclusión, de contienda, de expoliación, pero también de creación, de reinvención, de construcción, de reflexión y de distancia/acercamiento/inmersión/recorrido crítico. Porque el "territorio es sinónimo de apropiación, de subjetivación fichada sobre sí misma. Es un conjunto de representaciones las cuales van a desembocar, pragmáticamente, en una serie de comportamientos, inversiones, en tiempos y espacios sociales, culturales, estéticos, cognitivos" (Guattari y Rolnik, 1996:21).

En suma, Bordes (Todas las utopías son deprimentes) genera hilvanes sutiles en forma de incrustaciones fugaces sobre un territorio resquebrajado, pero que a su vez es un territorio que resiste a los embates de las utopías "modernizadoras", de las tecnocracias hipnotizantes, a partir de una contra-urbanística en los pliegues de la propia ciudad. Nuestras derivas y las creaciones que de ellas fueron surgiendo crearon nuevas huellas allí donde el territorio brama su dimensión ch'ixi.

\section{Puntadas finales}

El discurso decolonial, lejos de autoconfinarse en los límites de la neutralidad de una supracategoría formal, apunta a poner en evidencia la parcialidad de la construcción epistémica oculta detrás de discursos hegemónicos y pretendidamente universales. Poner en crisis los presupuestos sobre los que se edifican los discursos del conocimiento significa templar una voz que, eventualmente, conduzca a una posibilidad relacional de desenmascaramiento de los espejismos de una modernidad que "cajanegriza" el pensamiento. Citando a Bruno Latour,

[...] el camino mediante el cual el trabajo científico o técnico se vuelve invisible a causa de su propio éxito. Cuando una máquina funciona eficientemente o un hecho está establecido con firmeza, uno sólo necesita concentrarse en los beneficios que genere y no es su complejidad interior. Así, paradójicamente, sucede que la ciencia y la tecnología cuanto más éxito obtienen más opacas se vuelven (Latour, 2001:362).

Es así como, a través de desnudar una episteme que opera como veladura, podríamos definir el lugar desde donde el discurso se enuncia - parecerían decirnos los teóricos decoloniales-. Desde esta aproximación a ciertas prácticas subalternas en el campo de las creaciones tecnoartísticas en el contexto latinoamericano, el diálogo entre lo artístico y lo tecnológico supondría alumbrar cuestiones cruciales a la hora de desmalezar el terreno donde confluyen lenguajes, formatos y discursos que abrevan tanto en su contexto como en el potencial que la propia tecnología trae consigo. Los conceptos de "mestizaje" 
y de "hibridación" tienen ciertas limitaciones a la hora de observar y de explorar prácticas situadas en donde confluyen la situacionalidad con tecnologías portadoras de discursos profundamente anclados en una dimensión tecnocientífica hegemónica. En uno de los conceptos prevalece la noción de resultado (mestizaje) sobre la procesualidad, y el otro habilita la posibilidad de instancias de fusión (hibridación) que limitan el análisis de aquellos proyectos en los que lo central y lo periférico cohabitan disonantemente en la propia materialidad de la obra - en términos matéricos y discursivos-. El concepto ch'ixi, este mestizaje disidente que destierra la ilusión de homogeneidad para instalar lo heterogéneo en tanto voz contenciosa, resulta, en cambio, más idóneo y más propicio al habilitar las tensiones, las disrupciones y las confrontaciones en su dinámica constructiva. Así, las prácticas artísticas situadas, en las que estos encuentros y fricciones se producen, operan, consecuentemente, desde el desarme y no desde el resultado. Porque, ¿cómo sería posible que las fricciones emerjan si no es desde el desguace?, ino es la expectativa de un resultado - y no de un proceso- - lo que difumina las propias acciones no permitiendo, por ende, visualizar, poner en juego, amplificar esta tensión que emerge del propio acto de desguazar los objetos y sus formas, las tecnologías y sus cuestionamientos críticos, los territorios y sus enmascaramientos? Así, allí donde lo ch'ixi orienta los principios constructivos, las operatorias y las acciones poéticas, se producen ciertos atisbos de desguaces del orden de lo poético, de lo epistémico o de la propia construcción tecnológica que refieren al propio hacer y su situacionalidad.

Lejos de pretender realizar una sistematización unificadora en nuestro contexto -y mucho menos conclusiva, como se señala al inicio-, esta contribución pretende generar una aproximación inestable y provisoria de ciertos gestos que ponen en crisis los presupuestos de las cajas negras, en la que el concepto de ch'ixi es una herramienta posible para desarmar la problemática relación entre arte y tecnología. Insisto, es solo una mirada parcial y perecedera porque de eso se trata esta dimensión ch'ixi, de estas "formas disruptivas y contenciosas de expresar sus dilemas" (Rivera, 2019a:23).

\section{Notas}

1 Uso el neologismo "occidocentrista", derivado del término "occidocentrismo" —empleado por diversos autores de las ciencias sociales- para caracterizar a aquellas visiones centradas en la occidentalidad hegemónica, que no necesariamente provienen del mundo occidental, y que ignoran aquellas voces sustentadas por otros universos paradigmáticos. Lo occidocentrista engloba las posiciones eurocentristas, antropocentristas, etnocentristas y patriarcales resultantes de la ideología de la modernidad. En definitiva, derivan de una noción de colonialidad que tiene su origen en un "eurocentrismo pervasivo $-\mathrm{O}$, como mejor debemos llamar, occidocentrismopor parte de los teóricos académicos para quien el colonialismo figura, narcisísticamente, como una proyección (el deseo de Occidente por el poder, etc.)". Traducción propia de: "pervasive Eurocentrism -or, as we might better term it, Occidocentrism' on the part of academic theorists, for whom colonialism figures, narcissistically, as a projection (the wester will to power, etc.)" (Wolfe, 1997:57).

2 Tomando los conceptos de Mark Tuters, por prácticas tecnológicas situadas aludo a "cómo los medios interactivos sutilmente afectan la relación entre humanos con el entorno, estructurando la subjetividad en la medida en que nos relacionamos a través de aparatos interactivos". Traducción propia de: "how interactive media subtly effect the relationship of humans to the environment, structuring subjectivity as we relate through our interactive apparatuses" (Tuters, 2011).

3 "[...] un dispositivo es esto: unas estrategias de relaciones de fuerzas soportando unos tipos de saber, y soportadas por ellos" (Foucault, 1991:130).

4 Entrevista inédita a Gabriela Munguía realizada en agosto de 2017.

5 Para documentación visual y textual sobre la obra, véase: http://www.gabrielamunguia.com/portfolio/ habitaculos-organicos/ (consultado en abril de 2020).

- La teoría de las "arquitecturas de subsunción" de Rodney Brook tenía por objetivo resolver inteligencias 
más sencillas que permitieran crecer gradualmente en grados de complejidad. Este abordaje de abajo hacia arriba (bottom-up) concibe la acción como resultante de la percepción, sin ningún tipo de intermediación de representaciones simbólicas. En este esquema, los comportamientos están ordenados por capas, siendo los de las capas más bajas los de mayor prioridad y, por ende, aquellos que ocluyen a los de las capas superiores. La robótica basada en comportamientos deriva de esta perspectiva y concibe a los robots como "entidades físicas situadas en un entorno en el que los datos interpretados por sus sensores están directamente acoplados a las acciones que realiza el robot a través de unos módulos de comportamiento" (Bermejo, 2003:7).

7 Para mayor información sobre la experiencia de Fonoraggy véase: https://issuu.com/crudo.productora/ docs/federico_gloriani_corregido__forma y https:// issuu.com/crudo.productora/docs/fede_gloriani__los_ otros. Para documentación sobre la obra véase, https:// fedegloriani.wixsite.com/fede-gloriani/fonoraggy o https://www.youtube.com/watch?v=bINHPH7IL3o (consultado en abril de 2020).

8 En el sentido foucaltiano de episteme, es decir, aquel tipo de discurso que caracteriza una forma particular de conocimiento cultural, de sus instituciones y de sus formas de vida y de pensamiento: "el dispositivo estratégico que permite escoger entre todos los enunciados posibles, los que van a ser aceptables en el interior, no digo de una teoría científica, sino de un campo de cientificidad, y de los que se podrá decir: éste es verdadero o falso" (Foucault, 1991:131).

${ }^{9}$ Para mayor información, véase Yeregui (2011).

${ }^{10}$ Para mayor información sobre SEFT-1, véase: http:// www.ivanpuig.net/seft.html

${ }^{11}$ http://www.seftl.net/

${ }^{12}$ Hago alusión al título del libro de Rivera Cusicanqui (2019).

${ }^{13}$ Trabajo realizado a partir de la línea de investigación llevada a cabo en el marco del Grupo de Geopoéticas Subalternas, dentro del Laboratorio de Arte e Inteligencia Artificial de la Universidad Nacional de Tres de Febrero, como parte del programa INNOVART del Ministerio de Educación de la Nación, en asociación con la Universidad
Nacional de Misiones (Argentina), la Universidad Nacional de Avellaneda y la Escuela de Bellas Artes de Nantes (Francia).

14 Parkway o avenida parque, modelo de origen norteamericano de gran desarrollo entre las décadas de 1910 y 1930.

${ }^{15}$ El Gauchito Gil es un santo profano objeto de devoción popular en la Argentina.

\section{Referencias}

Bajtin, Mijail (1982). Estética de la creación verbal. México: Siglo XXI.

Barrios, José Luis (2011). “Acciones paralelas. Modernidad y alegoría de las vías imposibles: SEFT-1”. En Iván Puig y Andrés Padilla Domene (comp.). SEFT-1. México: CONACULTA, INBA, Laboratorio Arte Alameda, pp. 214-219.

Baudrillard, Jean (1984). Cultura y simulacro. Barcelona: Editorial Kairós.

Bermejo Sánchez, Sergi (2003) Desarrollo de robots basados en el comportamiento. Barcelona: Ediciones UPC.

Buck Morss, Susan (2005). Walter Benjamin, escritor revolucionario. Buenos Aires: Interzona.

Careri, Francesco (2016). Pensar, detenerse. Barcelona: Gustavo Gili.

Deleuze, Gilles (1990). "Conversaciones con Claire Parnet". Disponible en hhttp://estafetagabrielpulecio.blogspot.com/2009/08/gilles-deleuzeabecedario-entrevistas.html (consultado el 23 de septiembre 2019).

Deleuze, Gilles y Félix Guattari (2002). Mil mesetas. Valencia: Pre-textos.

Foucault, Michel (1991). "El juego de Michel Foucault". En Michel Foucault, Saber y verdad. Madrid: Ediciones La Piqueta, pp. 127-162.

García Canclini, Néstor (2001). Estudios latinoamericanos sobre cultura y transformaciones sociales en tiempos de globalización. Buenos Aires: CLACSO.

Grosfoguel, Ramón (2007). "Diálogos decoloniales con Ramón Grosfoguel: transmodernizar los feminismos". Entrevista realizada por Doris Lamos Canavate. En Tabula Rasa, 7, 323-340. 
Guattari, Felix y Suely Rolnik (2006). Micropolitica: cartrografías del deseo. Madrid: Traficantes de Sueños.

Kozak, Claudia (2014). "Introducción. De tensiones, confrontaciones y correspondencias". En Claudia Kozak (comp.),Poéticas/políticastecnológicasen Argentina (1910-2010). Paraná, Argentina: La Hendija, pp. 5-16.

Kusch, Rodolfo (2000). Obras completas, vol. 2. Santa Fe: Fundación Ross.

Latour, Bruno (2001). La esperanza de Pandora: ensayos sobre la realidad de los estudios de la ciencia. Barcelona: Gedisa.

Mignolo, Walter (2003). Historias locales/ diseños globales. Colonialidad, conocimientos subalternos y pensamiento fronterizo. Madrid: Akal.

Restrepo, Eduardo y Axel Rojas (2010). Inflexión decolonial: fuentes, conceptos y cuestionamiento. Popayán: Instituto de Estudios Sociales y Culturales Pensar, Maestría en Estudios Culturales, Universidad Javeriana, Universidad del Cauca.

Rivera Cusicanqui, Silvia (2015). Sociología de la imagen: miradas chixidesde la historia andina. Buenos Aires: Tinta limón.
Rivera Cusicanqui, Silvia (2019a). Un mundo ch'ixies posible. Buenos Aires: Tinta Limón.

Rivera Cusicanqui, Silvia (2019b). Entrevista (17 de febrero 1019). En AgenciadeNoticias RedAcción. Disponible en: https:// www.anred.org/2019/02/17/silvia-rivera-cusicanquitenemos-que-producir-pensamiento-a-partir-de-locotidiano/ (consultado el 23 de septiembre 2019).

Tuters, Marc (2011). "Forget Psychogeography: The Object-Turn in Locative Media". Disponible en: http://web.mit.edu/comm-forum/legacy/mit7/ papers/Tuters_DMI_MIT7.pdf (consultado el 23 de septiembre 2019).

Wolfe, Patrick (1997). "Should the subaltern dream? Australian Aborigines and the problem of ethnographic ventriloquism". En S.C. Humphreys (ed.), Cultures of scholarship. Ann Arbor: University of Michigan Press.

Yeregui, Mariela (2011). "Móviles en movimiento. Cuerpo y territorio en la escena posmedia". En G. Beiguelman y J. La Ferla (coords.), Nomadismos tecnológicos. Buenos Aires: Ariel.

\section{Imagen 1. Altar urbano}

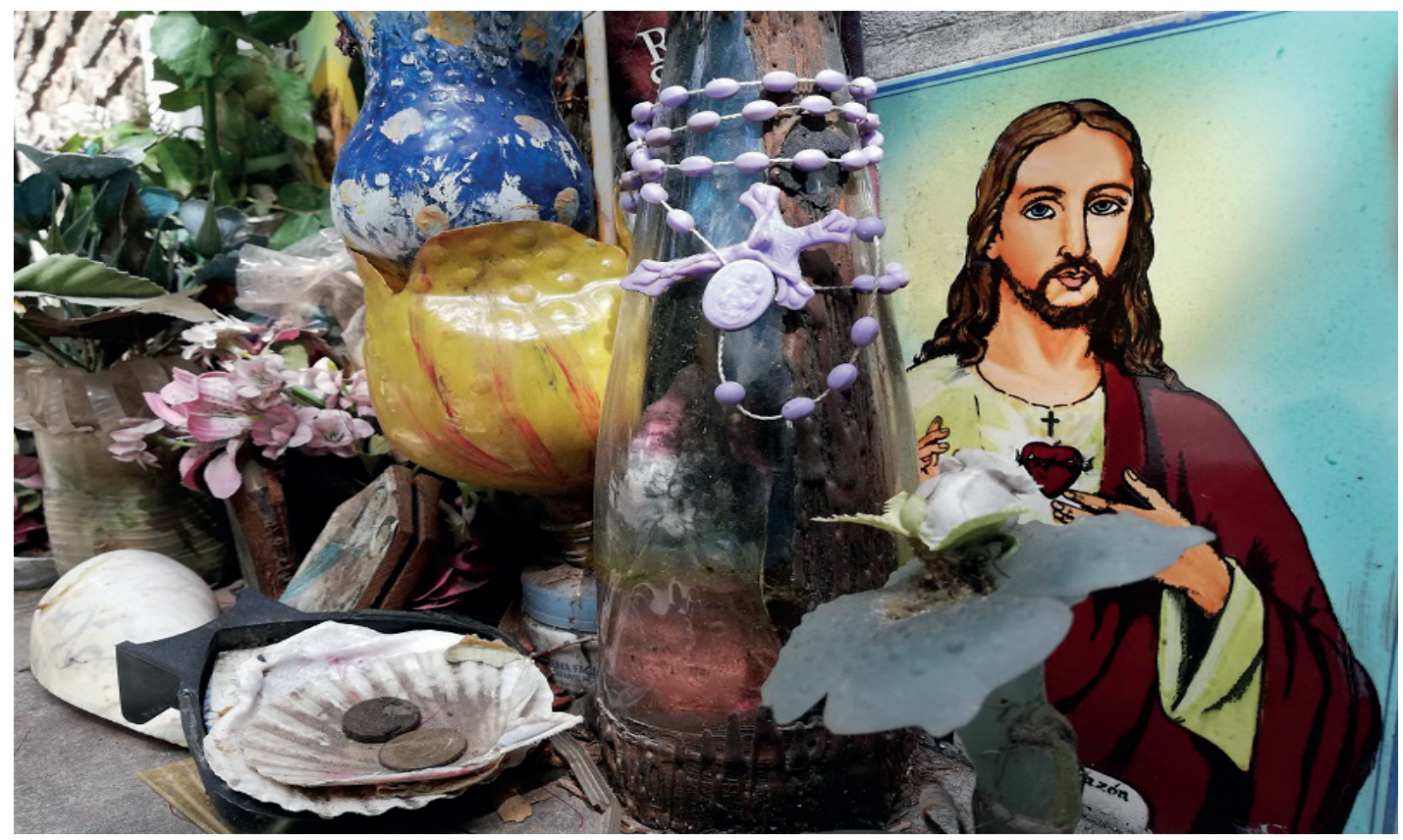

Fuente: Registro de acción. Marlin Velasco y Mariela Yeregui. 


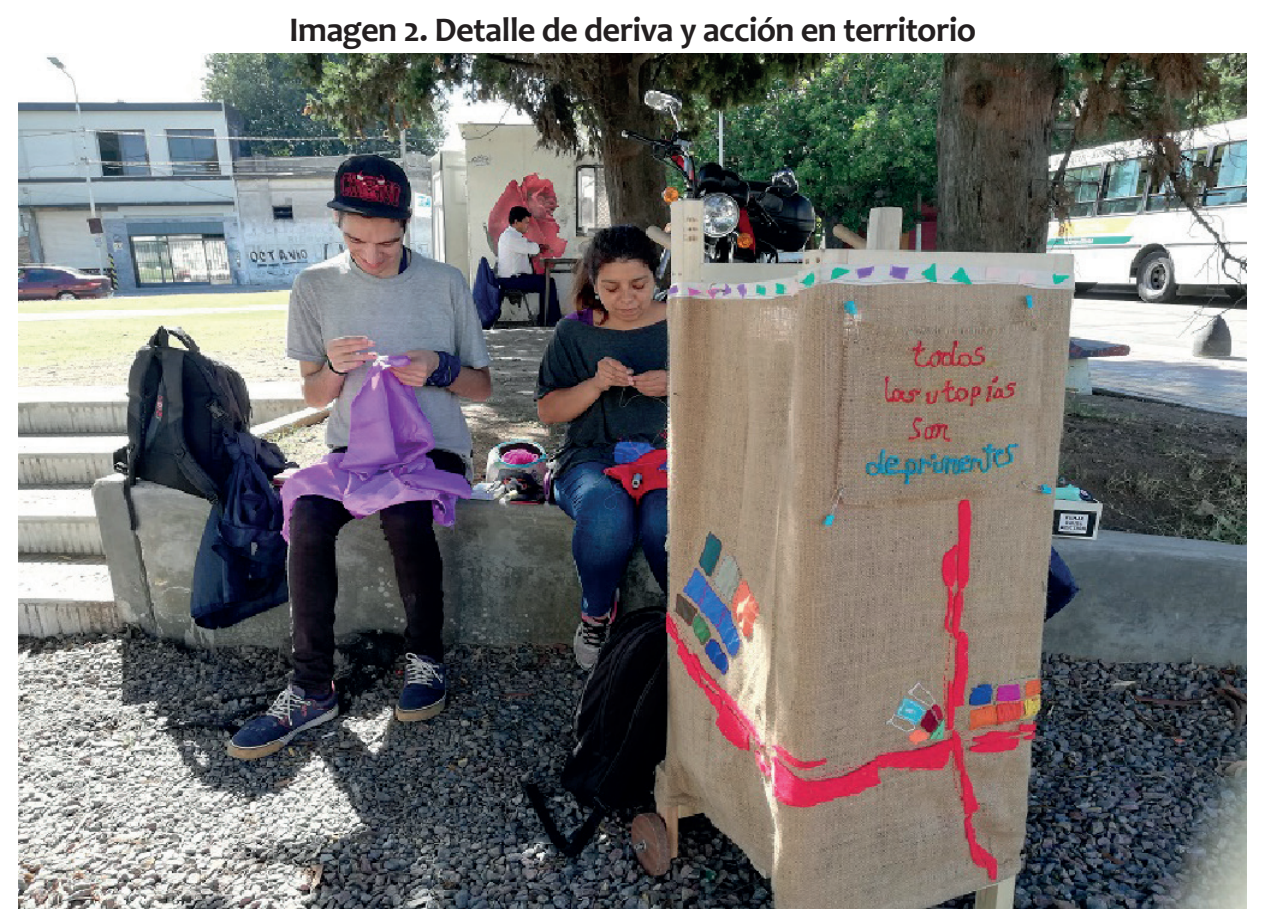

Fuente: Caseros, 2019.

\section{Imagen 3. Detalle mapa electro-textil}

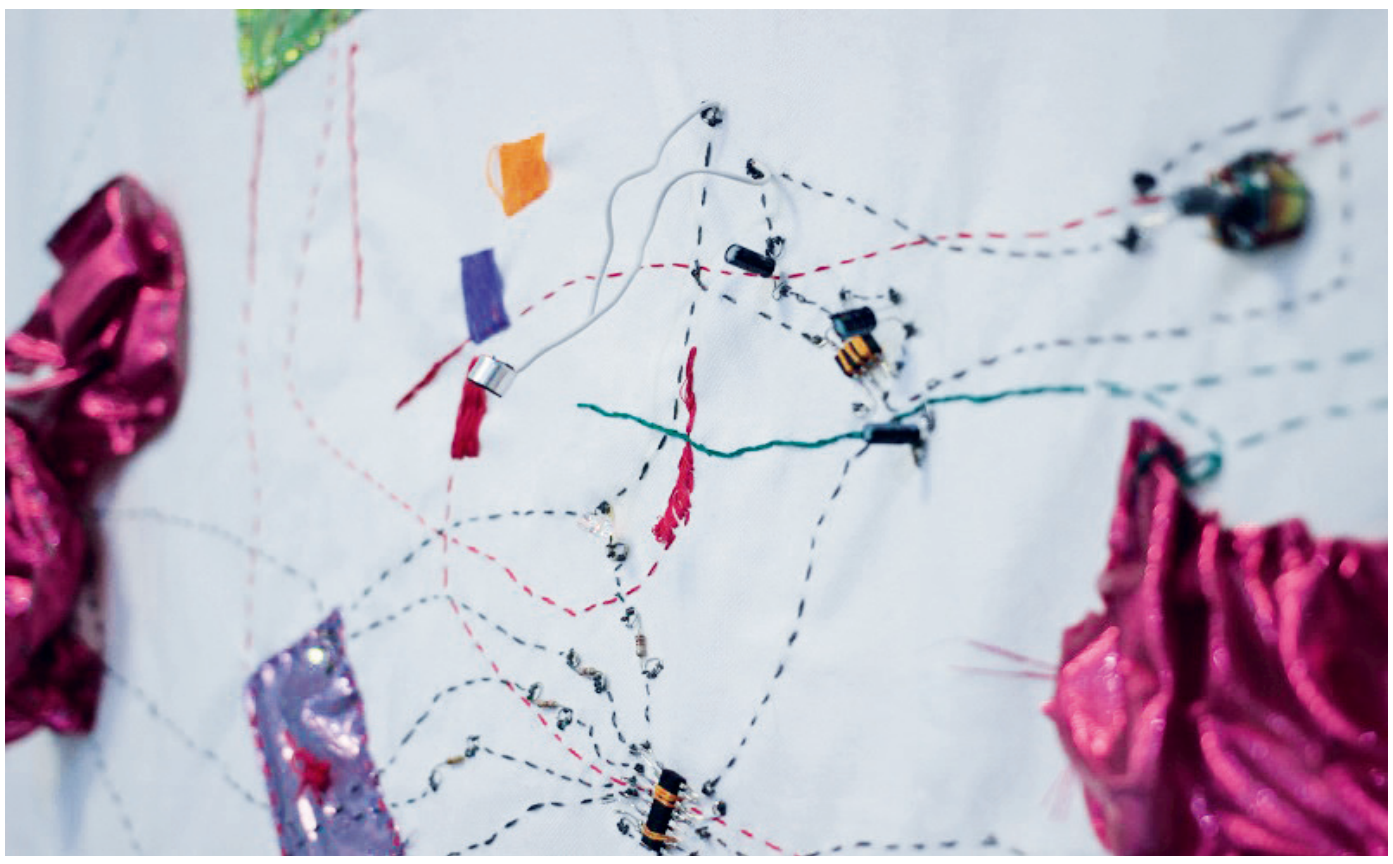

Fuente: Caseros, 2019. 


\section{Imagen 4. Acciones electro-arquitectónicas}

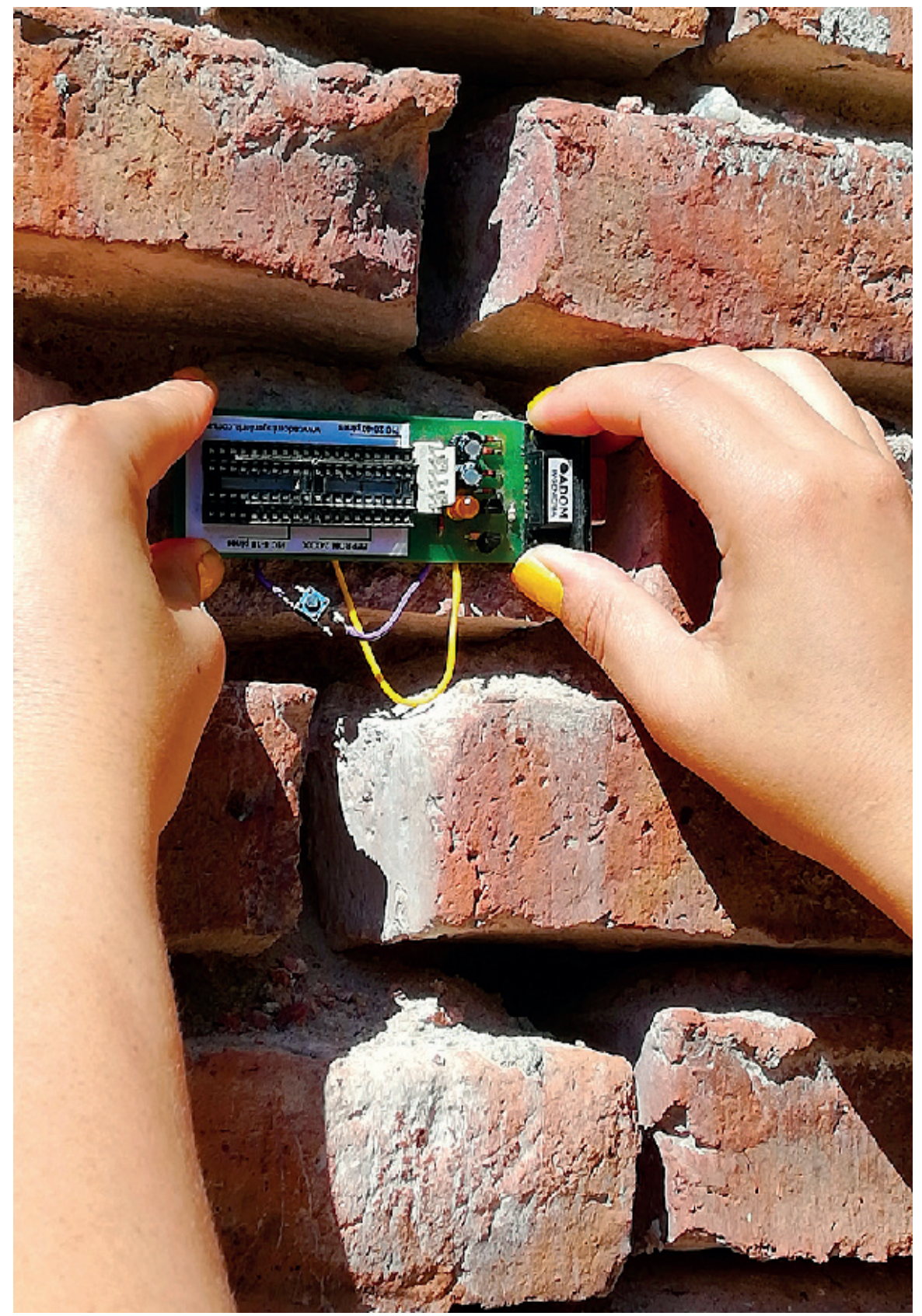

Fuente: Caseros, 2019. 